\title{
IL-2 Recombinant Fusion Protein ALT-801
}

National Cancer Institute

\section{Source}

National Cancer Institute. IL-2 Recombinant Fusion Protein ALT-801. NCI Thesaurus.

Code $C 71743$.

A recombinant protein consisting of the cytokine interleukin-2 (IL-2) fused to a

humanized soluble T-cell receptor (TCR) directed against a tumor suppressor p53-

derived antigen with potential immunopotentiating and antineoplastic activities. The TCR

moiety of IL-2 recombinant fusion protein ALT-801 binds to tumor cells displaying p53

epitope/MHC complexes; subsequently, the tumor cell-localized IL-2 moiety may

stimulate natural killer (NK) cell and T cell cytotoxic immune responses against p53-

expressing tumor cells. 